\title{
Factors Associated With Patient Waiting Time at a Medical Outpatient Clinic: A Case Study of University of Nairobi Health Services
}

\author{
Rebecca Bisanju Wafula ${ }^{* 1}$ (BSCN, MSCHSM), Dr. Richard Ayah ${ }^{2}$ (MBCHB, MSC, PHD) \\ ${ }^{1}$ University of Nairobi, School of Public Health, P.O. Box 865700200 \\ ${ }^{2}$ Senior Lecturer, University of Nairobi, School of Public Health, P.O. Box 3019700100 \\ *Corresponding Author: Rebecca Bisanju Wafula, (BSCN, MSCHSM); vis.wafula@gmail.com
}

Received 06 December 2021;

Accepted 22 December 2021;

Published 24 December 2021

\begin{abstract}
Background: Long waiting time in outpatient clinics is a constant challenge for patients and the health care providers. Prolonged waiting times are associated with poor adherence to treatment, missed appointment and failure or delay in initiation of treatment and is a major factor towards the perception of the patient towards the care received. Objective: To determine the waiting time and associated factors among out patients attending staff clinic at University of Nairobi health services. Method: A cross-sectional study design was used and data collected from 384 ambulatory patients over a period of four weeks using an interviewer administered pretested structured exit questionnaire with a time-tracking section. Simple random sampling was used to select respondents in a walk- in outpatient clinic set up. Data was cleaned and analysed using Statistical Package for Social Sciences (SPSS) 20. Analysis of variance (ANOVA), and cross tabulation was used to establish associations between the independent variable and dependent variables. Results: In total 384 patients were tracked and interviewed. The average patient waiting time was 55.3mins.Most respondents (52\%) suggested that improving availability of staff at their stations would help to reduce patient waiting time. In this study, gender $(\mathrm{P}=0.005)$ and availability of doctors $(\mathrm{p}=0.000)$ were found to affect patient waiting time with women waiting longer than the male patients. Conclusion: Majority of the patients spent about an hour at the facility to be served. Inadequate number of health workers was the main cause of long waiting time.
\end{abstract}

Keywords: patients waiting time, outpatient clinic

\section{Introduction}

Many health care systems globally continue to grapple with lengthy waiting time for patients. For instance in United States (US), the long waits in emergency outpatient department is a serious problem. The average waiting times in this country is twice the recommended time for acute patients ${ }^{[1]}$. An international survey conducted by the Canadian Institute of Health information in 2012, showed that at least half of the patients take four hours to be given treatment. Consequences of long stays in the health facilities are poor treatment outcomes ${ }^{[2]}$. Studies have shown that these patients do not return to these facilities while others leave the facility without being attended to thus risking their health ${ }^{[3]}$. In a tertiary hospital in Nigeria, a study carried out in a busy outpatient unit showed that a patient who waited longer to be attended to had lower satisfaction levels. Most patients found a waiting time of less than 30 minutes acceptable while more than 60 minutes was not acceptable ${ }^{[4]}$. This study sought to assess the patient waiting time and identify associated factors using the queuing theory. UHS like many health facilities utilizes the single channel and several phases. Application of this theory is therefore important to help in predicting how long a patient should take to receive a particular service and this can be used to design facility specific patient management guidelines. This is where all patients register at one records office for file retrieval then move to one nursing station for vital signs observation, then they are sent to several consultation rooms.

\section{Method}

2.1 Design

This was a cross- sectional study of outpatients at a stand-alone outpatient clinic.

\subsection{Study area}

The study was carried out at the University of Nairobi health Services senior staff clinic (S.S.C) which is situated in the main campus along lower state house road. The clinic provides services to both staff and students of the University of Nairobi that are outside Nairobi County. 


\subsection{Sample size}

In total 384 respondents were recruited during the four week study period

\subsection{Sampling technique}

Simple random sampling was employed to select participants from all patients who attended the clinic each day during the four weeks period and the average was 100 patients per day. Therefore the sampling frame was all the 100 patients.

\subsection{Data collection}

The selected respondents were approached and requested for a written consent after explanation regarding what the research entailed. After consenting, the researcher or her assistants followed the respondent while recording the waiting time at each service point up to the last service point (pharmacy section) and interviewed the respondent using a structured questionnaire. This randomization approach was appropriate because patients were visiting the facility at different times.

\subsection{Data analysis}

The filled questionnaires were checked at the end of each day by the researcher to ensure completeness and accuracy. The data was stored safely and handled by the research team only. Data was entered into the Statistical Package for Social Sciences (SPSS) software cleaned, verified and analysed. The analysis for categorical data was done using cross tabulation where possible.
Analysis of variance (ANOVA) was used to compare the average patient waiting time (continuous variable) among two or more populations (categorical variables).

\section{Results}

\subsection{Patient waiting time}

On average patients took 55.3 minutes at the clinic and the longest service point average waiting time was at the doctor's area (13.1 minutes). This is shown in table 1 below

Table 1: Average waiting time at different service points

\begin{tabular}{|l|l|}
\hline Service point & $\begin{array}{l}\text { Average waiting time } \\
\text { (Minutes) }\end{array}$ \\
\hline Records office & 5.8 \\
\hline Nursing station & 7.8 \\
\hline Doctors area & 13.1 \\
\hline Pharmacy & 5.5 \\
\hline Average time spent at the facility & 55.3 \\
\hline
\end{tabular}

\subsection{Availability of health workers at their stations}

More than $95 \%$ of the other health care workers were at their working station except the doctors where only $86.4 \%$ were at their working stations during the four weeks study period. Data collection for this information was also impended by the nonuniform departure and arrival at different times of the shift in the day by the doctors. This is shown in figure 1 below.

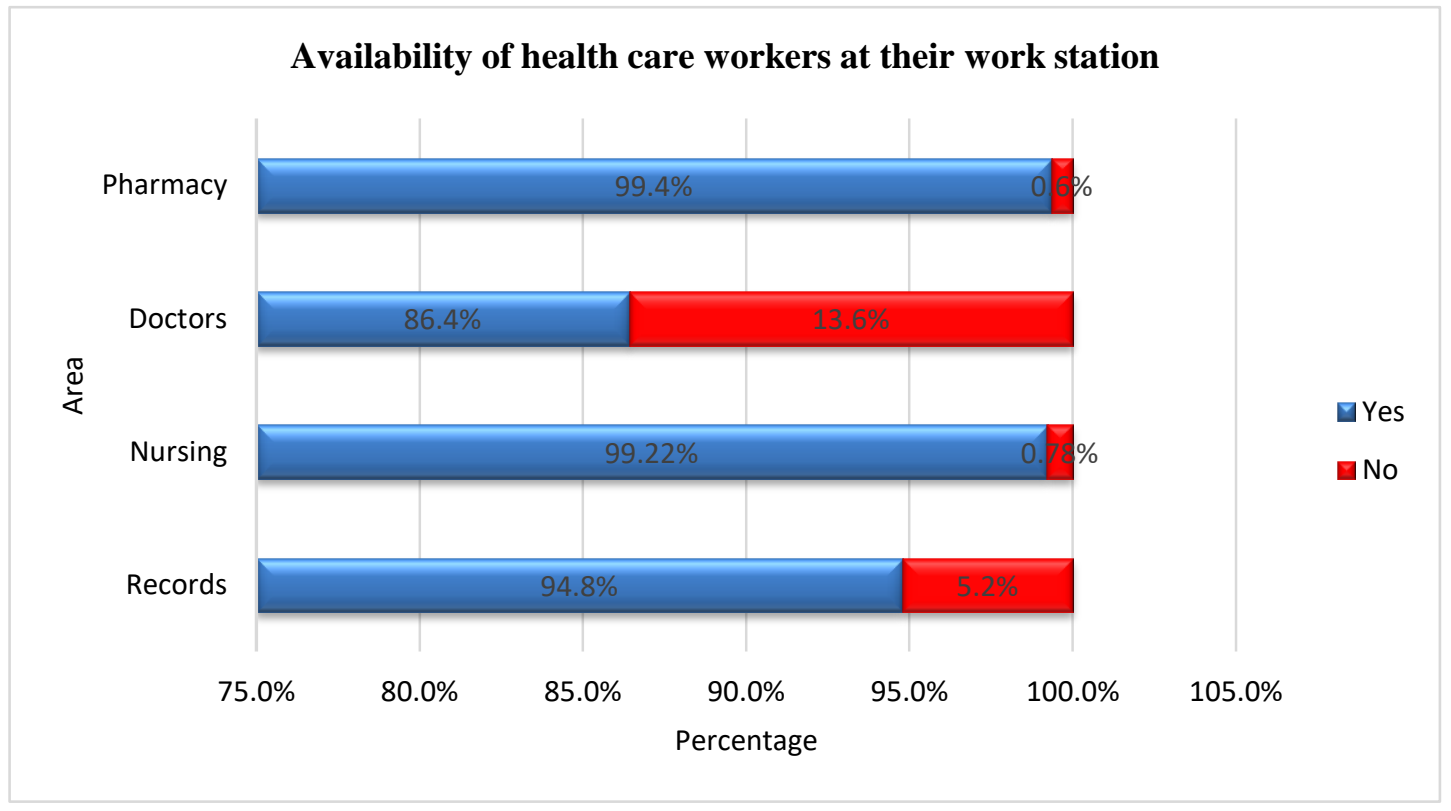

Figure 1: Availability of health care workers at their working stations

Majority $(96 \%)$ of the patients rated the waiting time at pharmacy as appropriate while the doctors was scored the least at $63 \%$

\subsection{Association between variables}

\subsubsection{Cross tabulation}

A cross tabulation to check overall acceptability of time spent in the clinic by gender showed that there is no significant difference with a chi square test value $\mathrm{P}=0.632$.
3.3.2 Analysis of variance for availability of doctors and patient waiting time

One way analysis of variance of total time spent against availability of doctors at the work station was conducted which showed a statistically significant difference showing that availability of doctors affect overall waiting time at the $\operatorname{clinic}(\mathrm{P}=$ 0.000 ) as shown in table 2 below.

Table 2: Availability of doctors and total time spent at the clinic

\begin{tabular}{|l|l|l|l|l|l|}
\hline & Sum of Squares & df & Mean Square & F & Sig. \\
\hline Between Groups & 71329.195 & 1 & 71329.195 & 69.746 & $\mathbf{. 0 0 0}$ \\
\hline Within Groups & 389650.800 & 381 & 1022.706 & & \\
\hline Total & 460979.995 & 382 & & & \\
\hline
\end{tabular}




\subsubsection{Analysis of variance for gender and total time spent}

A one way analysis of variance on gender and total time spent at the clinic showed a significance difference between male and females $(P=0.005)$ and thus a univariate analysis of variance was carried out to check for confounding and it was found to be still significant $(\mathrm{P}=0.001)$, the female was most affected as shown in table 3 below

Table 3: Gender and total time spent at the clinic

\begin{tabular}{|l|l|l|l|l|l|}
\hline & Sum of Squares & df & Mean Square & F & Sig. \\
\hline Between Groups & 9347.432 & 1 & 9347.432 & 7.923 & $\mathbf{. 0 0 5}$ \\
\hline Within Groups & 447155.644 & 379 & 1179.830 & & \\
\hline Total & 456503.076 & 380 & & & \\
\hline
\end{tabular}

\section{Discussion}

More than half of the respondents were female and this was shown to be significant. These findings are similar to other studies done in Nigeria, ${ }^{[5]}$ and other developed countries ${ }^{[6]}$ but percentage for the female was higher than that found in another study in Nigeria ${ }^{[4]}$. This study found that gender of the patient influenced waiting time which concurs with findings in similar studies ${ }^{[5]}$. The mean patient waiting time was found to be comparable to other findings in Nigeria ${ }^{[7]}$. While these findings contrast with findings in Malawi in a rural health centre ${ }^{[8]}$ which had a higher mean time. While most of the respondents spent one hour in the facility this average patient waiting time is lower than the average waiting time in Nigeria which was much higher ${ }^{[4]}$ but much higher than another ${ }^{[9]}$.

The mean waiting at UHS may further be improved therefore if the areas of delay are addressed. It is noteworthy that other studies have identified availability of health workers as important in reducing patient waiting time ${ }^{[10,5]}$. This study found that availability of health workers affected patient waiting time. Like the findings of this study, similar studies found that majority of patients arrive in the health facility in the morning hours ${ }^{[11]}$. The respondents rating of waiting time of services at each service points showed that most of them waited longest at the doctor's office. This concurs with other findings in similar studies ${ }^{[11,12]}$ but contrasts with another ${ }^{[13]}$ in Uganda that found out that registration and pharmacy areas had the longest waiting time. The two main suggestions from the respondents on how to reduce patient waiting time in the clinic were to improve the availability of health workers at their station and to increase staff per shift. These suggestions are more less the same with some given in another study ${ }^{[10]}$ and different from those suggested by respondents in Malaysia [14] however patient arrival time was not found to be a significant factor affecting patient waiting time in this study. It was also noted that the few patients who were given an appointment were not given a specific time for the appointment similar to another study in Uganda ${ }^{[11]}$.

In conclusion, the mean waiting time in senior staff clinic was about an hour to get the services needed which most patients felt was acceptable. The main cause of long waiting time was inadequate number of health workers. This may be the one of the first studies in a stand-alone outpatient medical clinic and therefore further studies are needed in this area that will involve healthcare workers and other qualitative data collection methods. In addition other proved ways of improving healthcare workers performance like capacity scenario challenges can be applied by managers in UHS to improve decision making on staffing levels that can provide optimal wait time reduction and hence improve service delivery to the university community. Thus there is need for UHS management to improve staffing levels of doctors in the clinic.

\section{Conflict of interest}

None declared

\section{Source of support}

Nil

\section{References}

[1] Horwitz, L.I., Green, J. \& Bradley, E.H., 2010. US Emergency Department Performance on Wait Time and Length of Visit. Annals of Emergency Medicine, 55(2), pp.133-141. Available at: http://www.annemergmed.com/article/S01960644090128 39/fulltext [Accessed November 11, 2016].

[2] Yeboah, E. \& Thomas, M., 2009. A cost effective way of reducing outpatient clinic waiting times: How we did it. 7(1), pp.6-9.Advances in urology, p.507436

[3] Nabbuye-Sekandi, J. et al., 2011. Patient satisfaction with services in outpatient clinics at Mulago hospital, Uganda. International journal for quality in health care : journal of the International Society for Quality in Health Care, 23(5), pp.516-523.23.Oche, M. \& Adamu, H., 2013. Determinants of patient waiting time in the general outpatient department of a tertiary health institution in north Western Nigeria. Annals of medical and health sciences research, 3(4), pp.588-592.

[4] Umar, I., Oche, M. O., \& Umar, A.S., 2011. Patient waiting time in a tertiary health institution in Northern Nigeria. Journal of Public Health and Epidemiology, 3(2), pp.78-82. Available at: http://www.academicjournals.org/jphe

[5] MO Oche \& H Adamu., 2013.Determinants of patient waiting time in the general outpatient hospital in Mulago. Ann. Med. HealthSci. Res 2013-oct-Dec3 (4) 588592.http://www.ncbi.nlm.nih.gov/PMC/articles/PMC386 8129

[6] Whyte, E. \& Goodacre, S., 2016. Patient expectations of emergency hospital admission: a cross-sectional questionnaire survey. European journal of emergency medicine: official journal of the European Society for Emergency Medicine, 23(3), pp.203-207.

[7] Okotie, O.T., Patel, N. \& Gonzalez, C.M., 2008. The effect of patient arrival time on overall wait time and utilization of physician and examination room resources in the outpatient urology clinic.

[8] Jafry, M.A. et al., 2016. Examination of patient flow in a rural health center in Malawi. BMC research notes, 9(1), p.363.Availableat:

http://www.ncbi.nlm.nih.gov/pubmed/27456090\%5Cn

[9] Chen, B. et al., 2010. Impact of adjustment measures on reducing outpatient waiting time in a community 
hospital: application of a computer simulation. Chinese medical journal, 123(5), pp.574-580.

[10] Ameh, N., Sabo, B. \& Oyefabi, M.O., 2013. Application of queuing theory to patient satisfaction at a tertiary hospital in Nigeria. Nigerian Medical Journal : Journal of the Nigeria Medical Association, 54(1), pp.64-67. 33.

[11] Wanyenze, R.K. et al., 2010. Evaluation of the efficiency of patient flow at three HIV clinics in Uganda. AIDS patient care and STDs, 24(7), pp.441-6. Available at: http://online.liebertpub.com/doi/abs/10.1089/apc.2009.03 28.

[12] Ho, E.T.L., 2014. Improving waiting time and operational clinic flow in a tertiary diabetes center. BMJqualityimprovementreports,2(2)http://www.pubmed central.nih.gov/articlerender.fcgi?artid=PMC4960743.

[13] Musinguzi, C., 2015. Patient waiting time and associated factors at the Assessment Center, General out-patient Department Mulago Hospital Uganda., (October).

[14] Pillay, D.I.M.S. et al., 2011. Hospital waiting time: the forgotten premise of healthcare service delivery?
International journal of health care quality assurance, 24(7), pp.506-522.

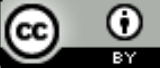

Open Access This article is licensed under a Creative Commons Attribution 4.0 International License, which permits use, sharing, adaptation, distribution and reproduction in any medium or format, as long as you give appropriate credit to the original author(s) and the source, provide a link to the Creative Commons license, and indicate if changes were made. The images or other third party material in this article are included in the article's Creative Commons license, unless indicated otherwise in a credit line to the material. If material is not included in the article's Creative Commons license and your intended use is not permitted by statutory regulation or exceeds the permitted use, you will need to obtain permission directly from the copyright holder. To view a copy of this license, visit https://creativecommons.org/licenses/by/4.0/.

(c) The Author(s) 2021 